\title{
Practical Issues in the Development of Argatroban: A Perspective
}

\author{
Jawed Fareed Debra Hoppensteadt Omer lqbal Mehmut Tobu \\ Bruce E. Lewis \\ Departments of Pathology and Pharmacology, Loyola University Medical Center, Maywood, III., USA
}

\section{Key Words}

Antithrombin - Anticoagulant - Thrombosis · Reversible inhibitor its thrombogenesis but also modulates cellular functions. Because of its broad spectral actions, argatroban will have more expanded indications.

Copyright $\odot 2002$ S. Karger AG, Basel

\begin{abstract}
Argatroban was the very first antithrombin agent that was approved for clinical use. It represents a synthetic arginomimetic drug with multiple pharmacologic properties. Unlike other antithrombin drugs, argatroban is a reversible antithrombin agent. Furthermore, it modulates endothelial cell function and downregulates various inflammatory and thrombotic cytokines. Argatroban is an effective anticoagulant agent, which at equivalent anticoagulant levels (activated clotting time; ACT) produces a stronger anticoagulant effect in comparison to heparins and hirudins. At a comparable ACT (300 s), argatroban produces much stronger inhibition of thrombin generation as measured by $F_{1.2}$ and thrombin-antithrombin complex generation. Argatroban does not generate any neutralizing or non-neutralizing antibodies and, therefore, it does not require any dosage adjustment during the course of therapy as other thrombin inhibitors require. The pharmacological profile of argatroban is unique as this antithrombin drug not only inhib-
\end{abstract}

\section{KARGER}

Fax + 41613061234

E-Mail karger@karger.ch

www.karger.com
(C) 2002 S. Karger AG, Basel

1424-8832/02/0329-0056\$18.50/0

Accessible online at:

www. karger.com/pht

\section{Introduction and Overview}

The central role of thrombin in coagulation and platelet activation is now well established. Thus, this enzyme provides an important target to control thrombogenesis [1-3]. Thrombin inhibitors such as recombinant hirudin, hirulog, and argatroban are currently being developed for various clinical indications [4-12]. These drugs produce a direct anticoagulant response by targeting thrombin and plasmatic and cellular sites dependent on thrombin. In addition to amplifying the coagulation cascade by activating factors $\mathrm{V}$ and VIII, mediating stabilization of fibrin by activating factor XIII and activating platelets, thrombin exerts several regulatory activities to maintain hemostatic balance. It is capable of activating protein $\mathrm{C}$, which is an anticoagulant and profibrinolytic enzyme [13]. Furthermore, thrombin is a potent stimulator of secretion of tissue-type plasminogen activator from endothelial cells [13-15]. Although plasminogen is activated to

Dr. Jawed Fareed, Professor of Pathology and Pharmacology

Director of Hemostasis Research Laboratories

Loyola University Chicago, Stritch School of Medicine

2160 South First Avenue, Maywood, IL 60153 (USA)

Tel. +1 708216 3262, Fax +1 708216 6660, E-Mail jfareed@lumc.edu 
plasmin directly by endogenous enzymes such as urokinase-type plasminogen activator and tissue-type plasminogen activator $[16,17]$, other enzymes such as kallikrein [18], factor XIIa [19], activated protein C [13, 14] and carboxypeptidase $\mathrm{U}$ (thrombin-activatable fibrinolytic inhibitor) also promote the activation of plasminogen. Some of the synthetic thrombin inhibitors are capable of producing inhibition of these enzymes [20-22]. Thus, both physiologic and pharmacologic fibrinolysis can be compromised. Thrombin inhibitors, therefore, exert a complex effect on the coagulation network and need to be carefully evaluated in clinical trials.

In the absence of heparin, thrombin is marginally neutralized by endogenous inhibitors such as heparin cofactor II and antithrombin, and because of their mass, these inhibitors are not capable of effectively neutralizing clotbound thrombin. On the other hand, the lower mass of thrombin inhibitors allows these agents to penetrate the thrombus and inhibit the thrombin contained within, to control further growth of the thrombus. Thus, smaller molecular weight thrombin inhibitors are capable of producing the inhibition of clot-bound thrombin and may be more effective than heparin. Direct thrombin inhibitors can be classified according to source (endogenous, analogues of natural substrates, recombinant and synthetic), structure and type of physiological interactions. Some of these agents are directed against the catalytic site of thrombin while others bind to the exosites of thrombin. In addition, some are reversible inhibitors while others are irreversible. A list of currently available site-directed thrombin inhibitors is given in table 1 . These agents are also depicted in figure 1 .
Among the natural thrombin inhibitors, hirudin is one of the most potent thrombin inhibitors, found in the saliva of the leech, Hirudo medicinalis. It is a single polypeptide chain of 65 amino acid residues, stabilized in a characteristic conformation by three disulfide bridges [23, 24]. Hirudin and its variants have been produced by recombinant technology. Point mutations to develop variant forms of hirudin have been used [25]. More recently, polyethylene glycol coupling of recombinant hirudin, to develop longer-lasting agents, has been accomplished [12]. Several experimental and clinical trials have shown that polyethylene glycol coupling of hirudin produces an increase in the efficacy of the drug. Various derivatives of hirudin

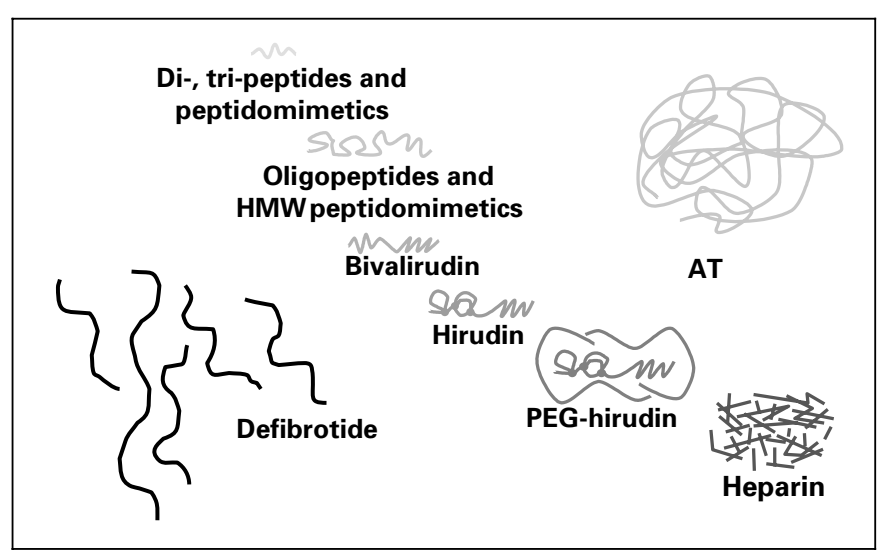

Fig. 1. A diagrammatic representation of various antithrombin drugs. As can be seen, the antithrombin agents represent a wide variety of chemical structures with functional and structural diversity.

Table 1. Developmental status of site-directed thrombin inhibitors

\begin{tabular}{lll}
\hline Agents & Chemical nature & Developmental status \\
\hline $\begin{array}{l}\text { Hirudin, PEG-hirudin } \\
\text { and related variants }\end{array}$ & $\begin{array}{l}\text { recombinant analogues of natural hirudin } \\
\text { and their derivatives }\end{array}$ & $\begin{array}{l}\text { various clinical phases of development; additional derivatives } \\
\text { are being developed; one product is available in Europe and USA }\end{array}$ \\
\hline Bivalirudin & synthetic bifunctional oligopeptides & $\begin{array}{l}\text { phase II and III clinical studies completed; available in USA; } \\
\text { additional studies are being carried out }\end{array}$ \\
\hline $\begin{array}{l}\text { Peptidomimetics } \\
\text { synthetic heterocyclic derivatives }\end{array}$ & $\begin{array}{l}\text { phase II and III clinical development in the USA; } \\
\text { one product available in USA, Canada and Japan; } \\
\text { additional clinical development in USA and Europe }\end{array}$ \\
\hline $\begin{array}{l}\text { Peptides and } \\
\text { their derivatives }\end{array}$ & $\begin{array}{l}\text { peptide arginals and boronic acid peptide } \\
\text { derivatives }\end{array}$ & phase II clinical development of various products \\
$\begin{array}{l}\text { Aptamers and } \\
\text { defibrotide }\end{array}$ & $\begin{array}{l}\text { DNA- and RNA-derived oligonucleotides } \\
\text { with thrombin-binding domains }\end{array}$ & preclinical stage; limited animal data available \\
\hline
\end{tabular}


are being aggressively developed for several clinical indications.

Coupling of peptides that mimic the carboxy terminal of hirudin to peptides that are specific for inhibition of the catalytic site of thrombin (D-Phe-Pro-Arg) has led to the development of a series of chimeric molecules termed hirulogs, in which the amino terminus consists of the catalytic site-directed peptides, while the carboxy terminus consists of the 12 terminal residues of hirudin. The two moieties are linked together by a bridge of glycine residues of variable length. Thus, hirulogs inhibit thrombin by binding to both its catalytic site and its anion-binding exosite, thus conferring specificity to these molecules for thrombin. One formulation, bivalirudin, has been developed aggressively for several cardiovascular indications [27]. However, its superiority over heparin has not been established.

Synthetic inhibitors of thrombin have long been used for the inhibition of thrombin. Of these inhibitors, the peptide derivatives mimicking the cleavage site in fibrinogen and peptidomimetics have provided therapeutic agents which are currently developed for various clinical indications. Of these, the most successful agent is an arginomimetic drug, argatroban, which represents the first thrombin inhibitor in clinical use. This reversible thrombin inhibitor is a direct inhibitor of thrombin and was synthesized by Okamoto et al. [26] in 1980. Japan is the first country where this thrombin inhibitor was approved for the treatment of peripheral occlusive vascular disease in the early 1990s. Subsequently, this drug was approved for acute cerebral thrombosis and for anticoagulation in thrombophilic patients requiring hemodialysis. In the year 2000, argatroban was approved in the US for the anticoagulant management of patients with heparin-induced thrombocytopenia [9, 27]. In early 2002, the FDA approved its usage in the anticoagulant management of HIT requiring percutaneous intervention (PCI) [10]. In addition to these approved indications, argatroban is now under clinical development for use in thrombotic and ischemic stroke.

Argatroban belongs to the peptidomimetic (arginomimetic) group of drugs with multiple pharmacologic properties. Unlike the other antithrombin drugs, such as hirudins and bivalirudin, argatroban is a fast reversible antithrombin agent and therefore exhibits a considerably different pharmacological profile. Although argatroban is considered to be a member of the antithrombin drug family, its mechanisms of action include several other steps that are not fully explored at this time. These include the inhibition of non-thrombin serine proteases, direct effect on endothelial cells and vasculature and downregulation of various inflammatory and thrombotic cytokines.

Because of its relatively lower molecular weight, argatroban is capable of passing through endovascular and cellular barriers and could possibly, therefore, be more effective than heparins and hirudins in the antithrombotic management of microvascular disorders. Argatroban is an effective anticoagulant agent, which at equivalent anticoagulant levels (activated clotting time; ACT) produces a stronger inhibition of thrombin generation in comparison to heparins and hirudins. At an ACT of $300 \mathrm{~s}$, argatroban produces much stronger inhibition of thrombin generation as measured by prothrombin fragment $F_{1.2}$ and thrombin-antithrombin complex generation compared to heparin. Argatroban does not generate any neutralizing or non-neutralizing antibodies and, therefore, unlike lepirudin does not require any dosage adjustment due to the effects of drug-antibody interaction. It also does not produce individual variations between patients and has predictable clinical effects.

Beside the inhibition of thrombogenesis, argatroban also produces facilitation of blood flow, inhibition of platelet activation and endothelial cell stimulation. Not all of these mechanisms are related to the inhibition of thrombin. Unlike the tight binding thrombin inhibitors, argatroban does not compromise thrombin regulatory processes. Some of these regulatory actions are given below:

- inhibition of factor XIIIa;

- antagonism of protein $\mathrm{C}$ activation;

- activation of thrombin-activatable fibrinolytic inhibitor;

- inhibition of thrombin-mediated hemostatic effects of platelets;

- inhibition of the vasomodulatory effects of thrombin, and

- modulation of inflammatory cytokines.

\section{Developmental Issues}

Despite several advantages, further preclinical investigations are needed to validate the application of argatroban in additional clinical indications. The following represents a compilation of some of the potential questions related to the development of argatroban as an antithrombin drug. The responses to each of these questions are based on the available information. 


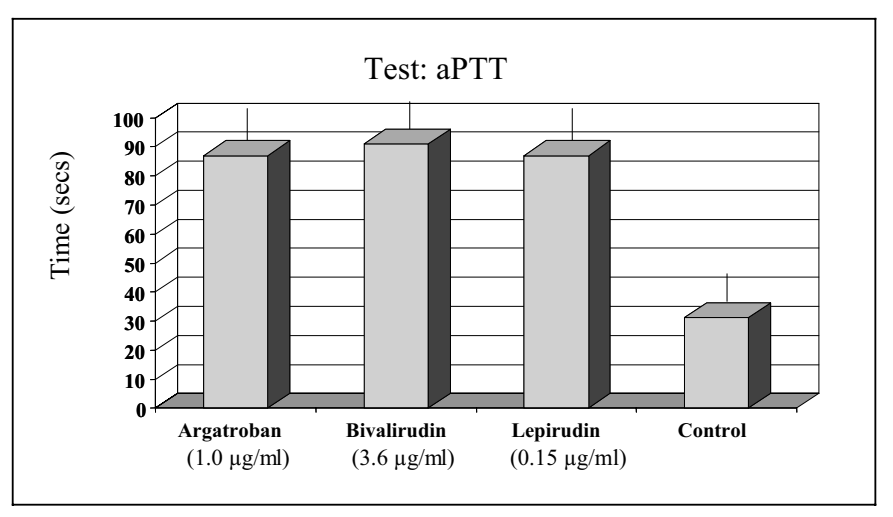

Fig. 2. Therapeutic anticoagulant effects of various anti-thrombin agents (aPTT 80-90 s). As can be seen, each drug produces the same prolongation of the aPTT at different concentrations. The mechanisms of their interactions are also different.

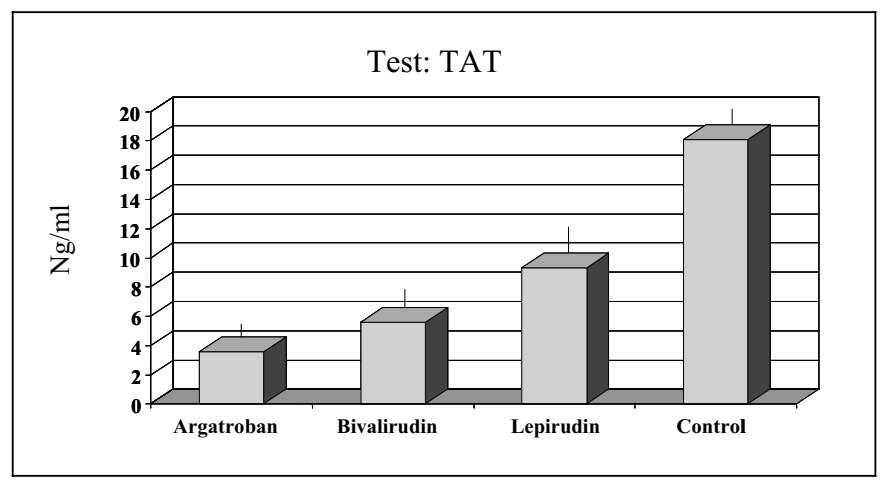

Fig. 3. Differential inhibition of thrombin-antithrombin complex by various thrombin inhibitors at equivalent therapeutic anticoagulant states (aPTT 80-90 s). As can be seen, each drug exhibits a specific inhibitory action. The order of potency is argatroban $>$ bivalirudin $>$ lepirudin.

\section{How Different Is Argatroban from Other Approved Antithrombin Agents?}

While thrombin inhibitors are usually evaluated in terms of their relative ability to inhibit the clotting or amidolytic actions of thrombin, their ability to inhibit thrombogenesis does not correlate with their antithrombin potency. Argatroban is a fast reversible inhibitor of thrombin. In contrast, hirudin and PEG-hirudin are slowly reversible inhibitors. Bivalirudin is also different from argatroban in terms of its mechanism of action as it is a bivalent inhibitor. As shown in figure 2, the relative concentrations needed to produce comparable prolongation of activated partial thromboplastin time (aPTT) to achieve therapeutic anticoagulation are quite different. At

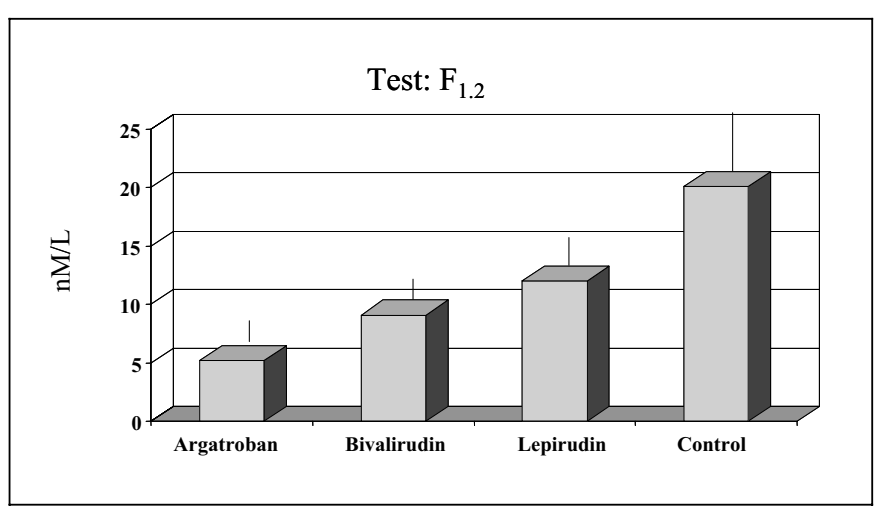

Fig. 4. Differential inhibition of $F_{1.2}$ generation by various thrombin inhibitors at equivalent therapeutic anticoagulant levels (aPTT 80$90 \mathrm{~s})$. As can be seen, each drug exhibits a specific inhibitory action. The order of potency is argatroban $>$ bivalirudin $>$ lepirudin.

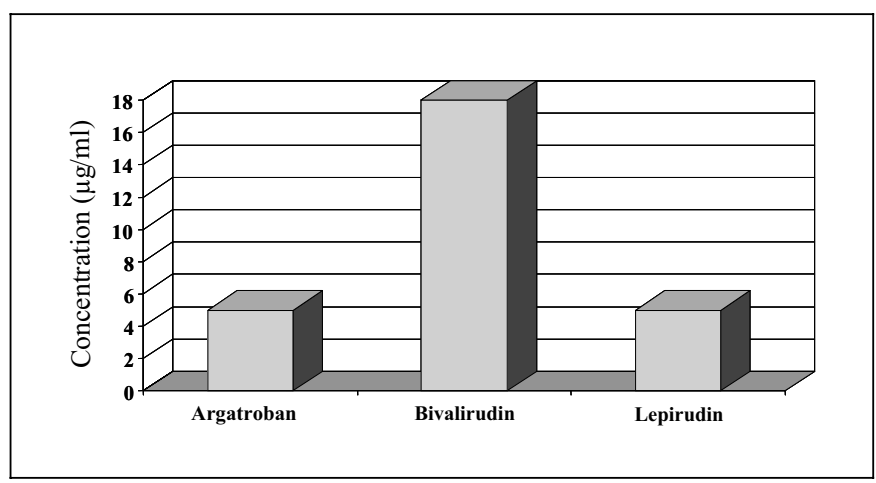

Fig. 5. Concentrations of thrombin inhibitors required to give ACT of $300 \mathrm{~s}$. Differential ACT prolongation by various thrombin inhibitors in human whole blood. Relatively higher concentrations are required to increase the prolongation of the ACT (to levels used in interventional procedures) compared to the aPTT.

these adjusted concentrations which produce equivalent anticoagulation, each of these inhibitors produces a different level of inhibition of thrombin generation. At the same level of anticoagulation, these three FDA-approved anticoagulants produce different degrees of inhibition in terms of the generation of thrombin-antithrombin complex (fig. 3) and prothrombin fragment $F_{1.2}$ (fig. 4). Similarly, each of these drugs produces prolongation of the $\mathrm{ACT}$ for PCI to $300 \mathrm{~s}$ at different concentrations, as shown in figure 5 . These pharmacokinetic and pharmacodynamic differences clearly indicate that each of these thrombin inhibitors is a distinct drug regardless of potency equivalence in clot-based or amidolytic assays. 
Fig. 6. Pharmacodynamics of various dosages of argatroban in primates as measured by the ACT. Because of the short half-life, a bolus followed by continuous infusion may be an optimal clinical approach.

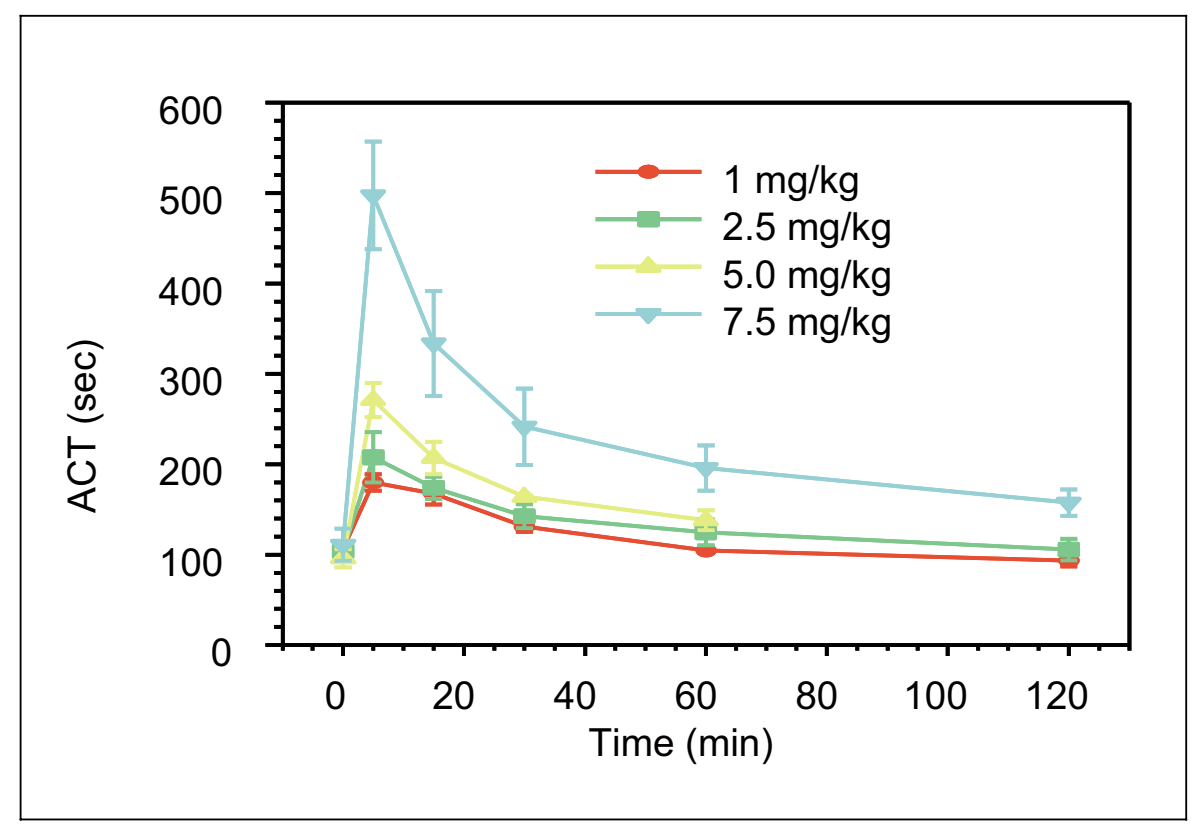

What Are Some of the Advantages of Argatroban as an Anticoagulant Agent over Other Antithrombin Agents?

Argatroban has several advantages over approved anticoagulant drugs such as heparins and hirudins. Firstly, argatroban does not require antithrombin for its anticoagulant actions. Secondly, it does not have the potential to cross-react with the heparin antibody. Thirdly, because of its short half-life, the effect of argatroban is readily reversible by discontinuation. These comparisons are in reference to heparin. These properties are also shared by other antithrombin agents such as hirudin. However, hirudin is a potent slowly reversible thrombin inhibitor that can compromise the biologic and regulatory effects of thrombin. Furthermore, hirudin can produce antibodies that can markedly influence its half-life. Thus, argatroban offers not only certain advantages over heparins but also over other thrombin inhibitors. Additional clinical trials are needed to demonstrate some of these differences.

\section{How Is the Effect of Argatroban Monitored?}

Monitoring of argatroban is required to optimize its usage. For therapeutic anticoagulation, monitoring is useful to maintain a steady concentration, particularly in patients with compromised renal and liver functions. In medical patients the aPTT is useful for therapeutic monitoring, however in studies in PCI, argatroban has been monitored by using the ACT. Figure 6 shows the effect of argatroban on the celite ACT after intravenous adminis- tration to primates. Dose-proportional increase in the celite ACT was observed. This suggests that the ACT is a reliable method for monitoring the anticoagulant effects of argatroban. The dosage selection of a $325 \mu \mathrm{g} / \mathrm{kg}$ bolus followed by a $25 \mu \mathrm{g} / \mathrm{kg} / \mathrm{min}$ infusion was capable of maintaining the ACT at 300-400 s. Proportionate prolongation of the ecarin clotting time (ECT) can also be seen (fig. 7). Both ACT and ECT are proportionate to the circulating argatroban levels in patients undergoing PCI [29, 30]. Based on these types of studies, PCI studies were carried out using argatroban at this dose. Of course, the influence of antiplatelet drugs in combination has to be investigated. The ACT provided a reliable guideline for achieving interventional anticoagulation.

Argatroban may also be effective in anticoagulation in patients undergoing bypass surgery. Of course, the dosage has to be optimized. A $500 \mu \mathrm{g} / \mathrm{kg}$ bolus, followed by a $50 \mu \mathrm{g} / \mathrm{kg} / \mathrm{min}$ infusion, may be suggested. Such dosing provides ACT levels in the range of 500-750 s.

In the Event of Argatroban Overdose, How Do We Neutralize the Anticoagulant and Bleeding Effects of Argatroban?

At the present time, there is no specific antidote for argatroban. In the event of an overdose of argatroban or in a patient with compromised clearance, argatroban's anticoagulant effects could theoretically be neutralized by the following methods: (1) hemofiltration or hemodialy- 


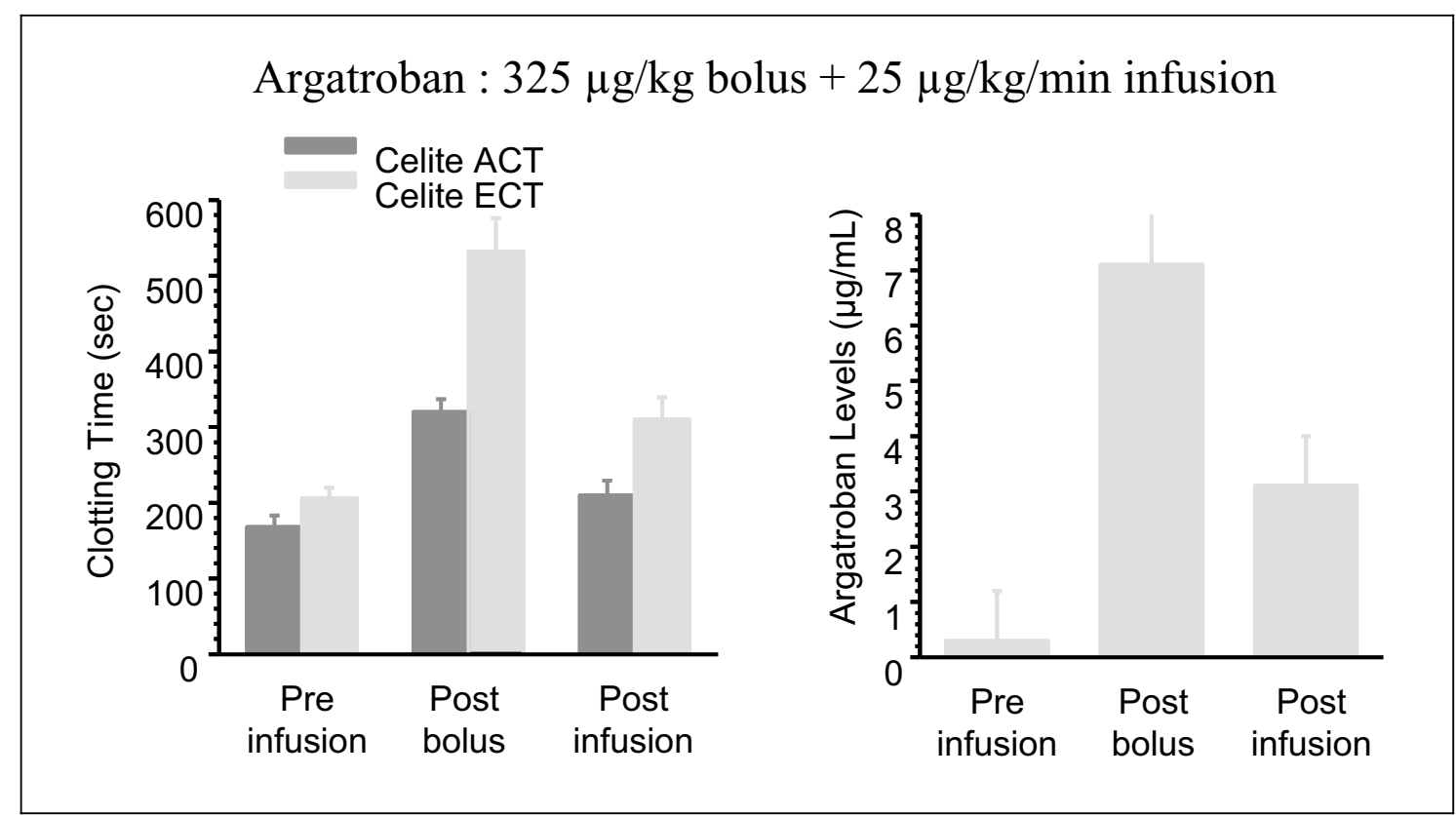

Fig. 7. ACT, celite ECT and absolute levels of argatroban in patients undergoing angioplasty and in patients undergoing percutaneous intervention. The circulating levels of argatroban are proportional to the prolongation of ACT.

sis; (2) plasmapheresis; (3) by treating patients with activated factor VII or prothrombin complex concentrate.

Other routine hemostatic measures can also be implemented.

Are All of the Clinical Effects of Argatroban Dependent on the Inhibition of Thrombin?

Although argatroban is primarily a direct thrombin inhibitor, the therapeutic impact of other potential actions of the molecule warrants further investigation. Argatroban is capable of producing several other effects on the hemostatic and vascular systems. This may or may not be dependent of the inhibition of thrombin. Argatrovan is able to produce the inhibition of platelet activation. As shown in figure 8 , argatroban strongly inhibited the thromboplastin-induced activation of platelets as measured by flow cytometry. P-selectin expression is strongly inhibited by argatroban. Argatroban is also capable of inhibiting the contraction of a rat aortic strip induced by endothelin I, as shown in figure 9. The exact mechanism by which this inhibition takes place is not known. However, a dose-dependent effect is quite clear. This indicates that argatroban may also modulate the vascular tone. As argatroban is an arginomimetic drug, it may have additional interactions with cellular and subendothelial sites.
Do We Expect to Observe the Same Drug Interactions with Argatroban and Antiplatelet Agents as Those Observed with Heparin and Antiplatelet Drugs?

The interactions between heparin and antiplatelet drugs are rather complex. However, both argatroban and heparin are antithrombin agents which can modulate platelet function. Unlike heparin, argatroban does not release tissue factor pathway inhibitor (TFPI) and other mediators from the vascular site. Furthermore, argatroban does not cause any mobilization of platelet factor 4 . Thus, the interaction between argatroban and antiplatelet drugs may be different in comparison to heparin and may merit further investigation.

\section{Does Argatroban Treatment Lead to the Generation of Antibodies?}

Argatroban treatment does not result in the generation of antibodies. This is in contrast to hirudin and hirulog, which are capable of generating these antibodies. These antibodies can seriously alter the treatment management. Argatroban is not a protein and its molecular weight is relatively low, thus it is unlikely that its use will result in the generation of antibodies [28]. 
Fig. 8. Argatroban-mediated inhibition of platelet activation as measured by a flow cytometric method. Argatroban produced inhibition of platelet activation.

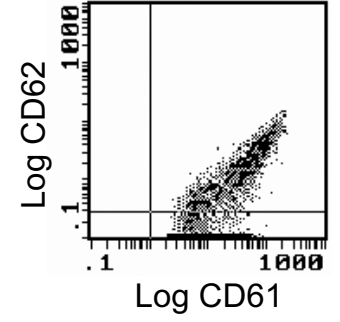

Control

33.3\% P-selectin expression (platelet gate)

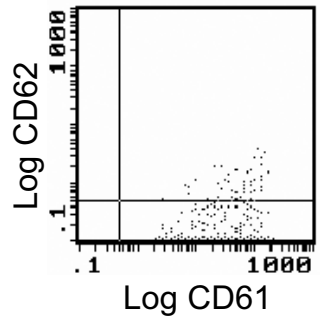

$0.4 \mu \mathrm{g} / \mathrm{mL}$ Argatroban

$0.9 \%$ P-selectin expression (platelet gate)

Fig. 9. Effect of argatroban on the endothelin-mediated contraction of rat aortic strip.

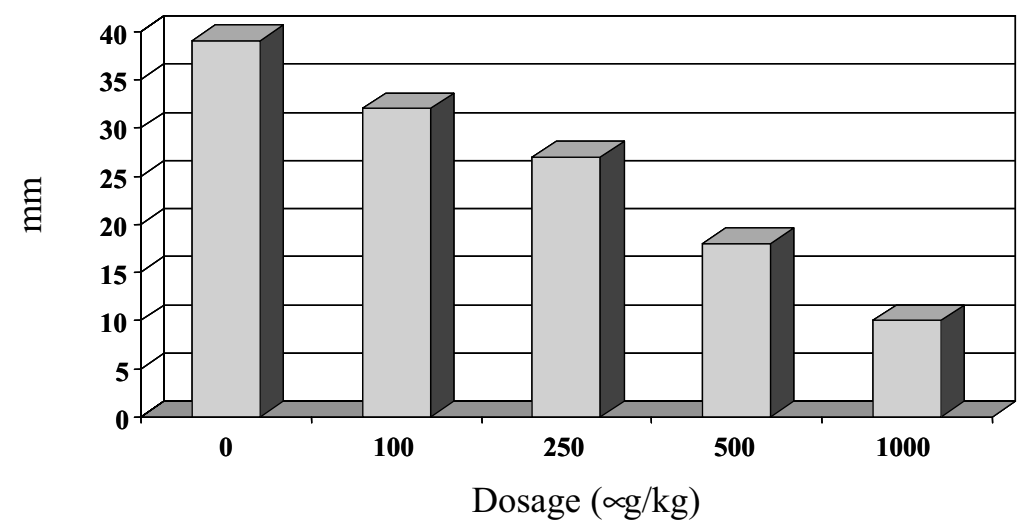

Can Argatroban Be Used in Pediatric Patients?

Argatroban is not approved for use in pediatric patients; however, with further study, it may be possible to use argatroban in this setting. It may be a relatively safer drug in comparison to heparin and hirudin.

Both heparin and hirudin have a relatively narrower therapeutic window than argatroban. Dose adjustment may be needed with argatroban for specific indications in pediatric patients.

\section{Can Argatroban Be Used in Pregnant and Nursing \\ Women?}

Teratology studies have been performed in rats with intravenous doses up to $27 \mathrm{mg} / \mathrm{kg} / \mathrm{day}$ ( 0.3 times the recommended maximum human dose based on body surface area) and rabbits at intravenous doses up to $10.8 \mathrm{mg} / \mathrm{kg} /$ day ( 0.2 times the recommended maximum human dose based on body surface area) and have revealed no evidence of impaired fertility or harm to the fetus due to argatroban.

There are, however, no adequate and well-controlled studies in pregnant women. Because animal reproduction studies are not always predictive of human response, this drug should be used during pregnancy only if clearly needed.

It is not known whether this drug is excreted in human milk. Because many drugs are excreted in human milk and because of the potential for serious adverse reactions in nursing infants from argatroban, a decision should be made whether to discontinue nursing or to discontinue 
Fig. 10. Possible future indications for argatroban. Although approved in specific indications, argatroban can readily be used in all of the intravenous indications where heparin is used.

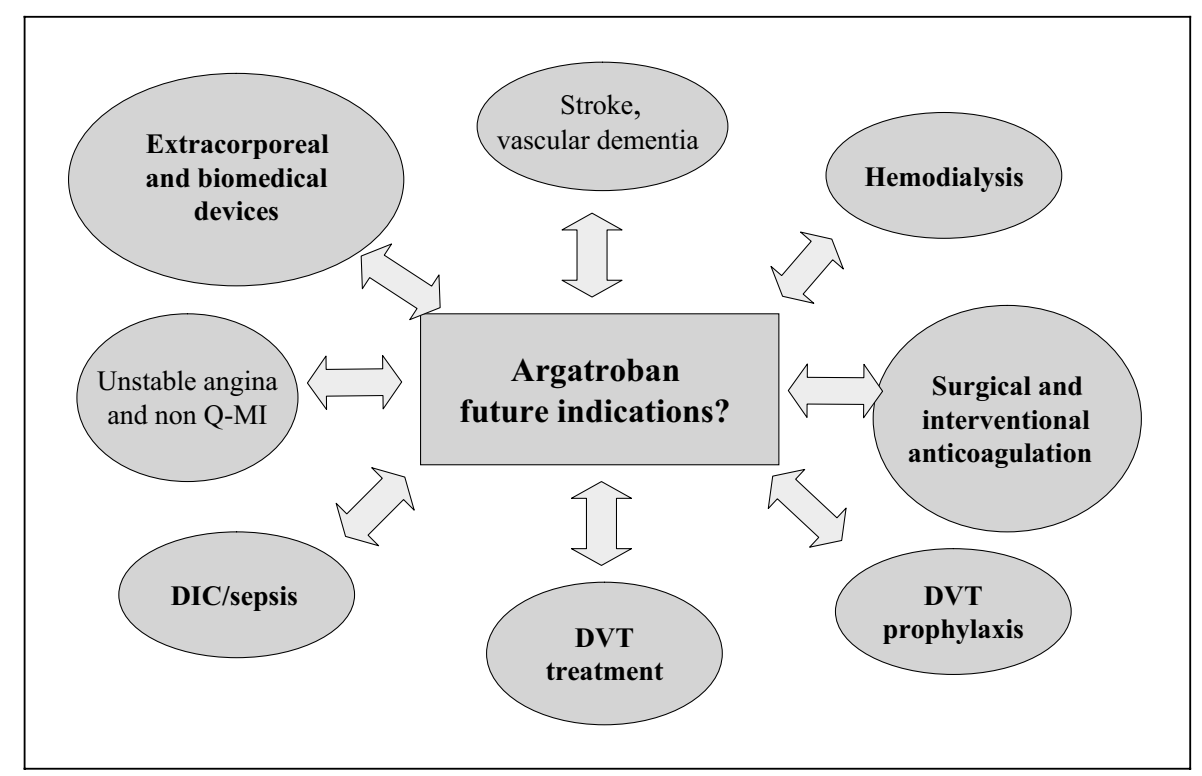

the drug, taking into account the importance of the drug to the mother.

\section{What May Be Future Indications for Argatroban?}

Currently, argatroban has been developed as an anticoagulant drug. In acute indications, argatroban may turn out to be a better drug than heparin because of its pharmacologic profile. Figure 10 lists some of the possible future indications in which argatroban may be used. In heparinand hirudin-compromised patients, argatroban may be effectively utilized as an anticoagulant drug. Argatroban may be used as an anticoagulant with biomedical devices. Hemodilution and other factors will not alter its action since the actions of argatroban are not dependent on antithrombin (AT). This agent may be used in hemodialysis; however, with a high flux machine, it is conceivable that some of the argatroban could be lost.

The FDA has recently approved the use of argatroban in PCI in HIT patients. Certainly, this agent may be used in non-HIT patients as well. As argatroban has proven efficacious in PCI, it is possible that at a $50 \%$ increased dosage, it could be used in surgical coronary artery bypass graft $(\mathrm{CABG})$. Argatroban may be useful in acute coronary syndromes. Thus, it may find expanded indications in various thrombotic and cardiovascular conditions.

Argatroban may have a specific use in off-pump cardiopulmonary bypass surgery. At relatively low dosages, this drug can be optimized for this indication. Because of its direct anticoagulant effect and relatively simpler structure, argatroban may be useful as a topical and local anticoagulant. Since hemodilution and hemoconcentration do not alter its anticoagulant actions, argatroban may be useful in adjunctive management of cancer and cancerassociated thrombosis. It may be the drug of choice for adjunct medication with antiplatelet and thrombolytic drugs. Argatroban could also be developed for surface coating of devices and stents. Because of its direct anticoagulant actions, it may be better than heparin. It can also be used for organ/cellular preservation. Argatroban has shown some antiinflammatory actions and as such could be developed as an antiproliferative agent.

\section{What Are Some of the Unresolved Issues in the Development of Argatroban?}

There are several unresolved issues in the development of argatroban as an anticoagulant, antithrombotic and antiischemic drug. Additional clinical trials are needed to demonstrate the antithrombotic and antiischemic effects of argatroban. Despite the profile of this drug and its usefulness in various indications, some of these developmental considerations remain unanswered at this time. Some of these are listed below:

(1) Effective and rapid reversal of the anticoagulant and potential bleeding effects of argatroban.

(2) Treatment of argatroban overdose.

(3) Safety with regard to passage across placental and blood brain barriers. 
(4) Effect of long-term usage of argatroban in specific indications.

(5) Monitoring issues for argatroban dosing and the selection of a suitable method.

(6) Concomitant use of argatroban with other drugs.

(7) Clinical validation of argatroban in specific indications in pediatrics.

(8) Elucidation of the additional mechanisms of action of argatroban.

(9) Effect of argatroban on the auto-regulatory process for the control of anticoagulation.

(10) Dosage optimization for specific groups of patients.

Argatroban is an anticoagulant drug which has been in clinical use for almost 11 years, with an acceptable safety and efficacy profile. Argatroban has been approved in the US for therapeutic and medical anticoagulation in heparin-compromised patients. If, in fact, this anticoagulant is useful in HIT patients, its efficacy may be comparable or better in non-HIT patients requiring anticoagulation. Therefore, it is important to develop this drug for wider use. It is likely that argatroban will prove to be efficacious in many of the indications where heparin is used intravenously. It is, however, important to know that there are basic differences between heparin and argatroban.

Since its introduction in the US, argatroban has been well accepted and it is likely to find additional clinical indications. With additional validation in specific clinical trials, this drug will make a major impact on the treatment of arterial and venous thrombosis.

\section{Acknowledgements}

The authors are highly indebted to Professor Okamoto, who has been the main inspiring individual in the continuing work on investigations into argatroban. This drug has provided a unique challenge to all of us and we will continue to probe the polypharmacologic action and endogenous interactions of this unique drug. A man of great vision and insight, Professor Okamoto's teachings will have a profound impact on our understanding of thrombosis and its management.

\section{References}

1 Fareed J, Lewis BE, Callas D, Hoppensteadt DA, Walenga JM, Bick RL: Antithrombin agents: The new class of anticoagulant and antithrombotic drugs. Clin Appl Thromb Hemost 1999;5(suppl 1):S45-S55.

2 Fareed J, Hoppensteadt DA, Bacher P, Messmore HL: Antithrombin agents: The new class of antithrombotic drugs; in Pifarre R, Scanlon PJ (eds): Evidence-Based Management of Acute Coronary Syndrome. Philadelphia, Hanley \& Belfus, 2001, pp 131-146.

3 Fareed J, Callas D, Hoppensteadt DA, Lewis BE, Bick RL, Walenga JM: Antithrombin agents as anticoagulants and antithrombotics: Implications in drug development. Semin Hematol 1999;36:42-56.

4 Fareed J, Callas D, Hoppensteadt D, Jeske W, Walenga JM: Recent developments in antithrombotic agents. Exp Opin Invest Drugs 1995;4:389-412.

5 Fareed J, Hoppensteadt DA, Breddin HK: Current perspectives in antithrombotic therapy. Hämostaseologie 2001;21:78-85.

6 Fareed J, Hoppensteadt DA: Antithrombin and anti-Xa agents in the control of thrombogenesis. Pharmazie 2001:56(suppl 1):S12-S21.

7 Jeske W, Walenga JM, Lewis BE, Fareed J: Pharmacology of argatroban. Exp Opin Invest Drugs 1999;8:625-654.

8 Kaiser B, Callas D, Walenga JM, Fareed J: Synthetic and recombinant antithrombin drugs. Exp Opin Invest Drugs 1998;7:963-985.
9 Lewis BE, Wallis DE, Berkowitz SD, Matthai WH, Fareed J, Walenga JM, Bartholomew J, Sham R, Lerner RG, Zeigler ZR, Rustagi PK, Jang IK, Rifkin SD, Moran J, Hursting MJ, Kelton JG, for the ARG-911 Study Investigators: Argatroban anticoagulant therapy in patients with heparin-induced thrombocytopenia. Circulation 2001;103:1838-1843.

10 Lewis BE, Ferguson JJ, Grassman ED, Fareed J, Walenga JM, Joffrion J, Wrona L, Johnson SA, Schwarz RP, McKiernan T: Successful coronary interventions performed with argatroban anticoagulation in patients with heparin-induced thrombocytopenia and thrombosis syndrome. J Invasive Cardiol 1996;8:410-417.

11 Topol EJ, Bonan R, Jewitt D, Sigwart U, Kakkar VV, Rothman M, de Bono D, Ferguson J, Willerson JT, Strony J, Ganz P, et al: Use of a direct antithrombin, hirulog, in place of heparin during coronary angioplasty. Circulation 1993;87:1622-1629.

12 Zawilska K, Zozulinska M, Turowiecka Z, Blahut M, Drobnik L, Vinazzer $H$ : The effect of a long-acting recombinant hirudin (PEG-hirudin) on experimental disseminated intravascular coagulation (DIC) in rabbits. Thromb Res 1993;69:315-320.

13 Sakata Y, Curriden S, Lawrence D, Griffin JH, Loskutoff DJ: Activated protein C stimulates the fibrinolytic activity of cultured endothelial cells and decreases antiactivator activity. Proc Natl Acad Sci USA 1985;82:1121-1125.
14 De Fouw NJ, van Hinsberg VW, de Jong YF, Haverkate F, Bertina RM: The interaction of activated protein $\mathrm{C}$ and thrombin with the plasminogen activator inhibitor released from human endothelial cells. Thromb Haemost 1987;57:176-182.

15 Dichek D, Quertermous T: Thrombin regulation of mRNA levels of tissue plasminogen activator inhibitor-1 in cultured human umbilical vein endothelial cells. Blood 1989;74:222228.

16 Collen D, Lijnen HR, Todd PA, Goa KL: Tissue-type plasminogen activator: A review of its pharmacology and therapeutic use as a thrombolytic agent. Drugs 1989;38:346-388.

17 Hoylaerts M, Rijken D, Lijnen HR, Collen D: Kinetics of the activation of plasminogen by human tissue plasminogen activator. Role of fibrin. J Biol Chem 1982;257:2912-2919.

18 Coleman RW: Activation of plasminogen by human plasma kallikrein. Biochem Biophys Res Commun 1968;35:273-279.

19 Goldsmith GH, Saito H, Ratnoff OD: The activation of plasminogen by Hageman factor fragments. J Clin Invest 1978;62:54-60.

20 Barabas E, Szell E, Bajusz S: Screening for fibrinolysis inhibitory effect of synthetic thrombin inhibitors. Blood Coagul Fibrinolysis 1993;4: 243-248.

21 Callas D, Bacher P, Iqbal O, Hoppensteadt D, Fareed J: Fibrinolytic compromise by simultaneous administration of site-directed inhibitors of thrombin. Thromb Res 1994;74:193-205. 
22 Gilboa N, Villannueva GB, Fenton JW II: Inhibition of fibrinolytic enzymes by thrombin inhibitors. Enzyme 1988;40:144-148.

23 Dodt J, Kohler S, Schmitz T, Wilhelm B: Distinct binding sites of Ala 48-hirudin 1-47 and Ala 48-hirudin 48-65 on $\alpha$ thrombin. J Biol Chem 1990;265:713-718.

24 Petersen TE, Roberts HR, Sottrup-Jensen L, Magnusson S: Primary structure of hirudin, a thrombin-specific inhibitor; in Peters H (ed) Peptides of the Biological Fluids. Oxford, Pergamon, 1976, pp 145-149.

25 Scharf M, Engels J, Tripier D: Primary structures of new 'isohirudins'. FEBS Lett 1989;225: 105-110.
26 Okamoto S, Hijikata A, Kikumoto R, Tonomura S, Hara H, Ninomiya K, Maruyama A, Sugano M, Tamao Y: Potent inhibition of thrombin by the newly synthesized derivative No. 805 . The importance of stereo structure of its hydrophobic carboxamide portion. Biochem Biophys Res Commun 1981;101:440-446.

27 Walenga JM, Jeske WP, Wood JJ, Ahmad S, Lewis BE, Bakhos M: Laboratory tests for heparin-induced thrombocytopenia: A multicenter study. Semin Hematol 1999;36(suppl 1):2228.

28 Walenga JM, Ahmad S, Hoppensteadt D, Iqbal $\mathrm{O}$, Hursting MJ, Lewis BE: Argatroban therapy does not generate antibodies that alter its anticoagulant activity in patients with heparininduced thrombocytopenia. Thromb Res 2002; 105:401-405.
29 Ahmad S, Ahsan A, Iqbal O, Hoppensteadt DA, Lewis BE, Walenga JM, Fareed J: Pharmacokinetics and pharmacodynamics of argatroban as studied by HPLC and functional methods: Implications in the monitoring and dosage-optimizations in cardiovascular patients. Clin Appl Thromb Hemost 1998;4:243-249.

30 Callas D, Fareed J: Comparative anticoagulant effects of various thrombin inhibitors, as determined in the ecarin clotting time method. Thromb Res 1996;83:463-468. 